\author{
Adam Muc \\ Lech Murawski \\ Adam Szeleziński
}

\title{
METHODS OF CRACKS DETECTION IN MARINE STRUCTURES' WELDED JOINTS BASED ON SIGNALS' TIME WAVEFORM ANALYSIS
}

\author{
UDC 629.5.015.4:629.5.083:620.193 \\ Preliminary Communication
}

\begin{abstract}
Summary
The paper presents two methods of crack detection in ship hulls. The methods are dedicated for structural health monitoring (SHM) of responsible welded joints. The system will be based on vibrodiagnostic - signals will be measured by piezoelectric accelerometers and/or fibre optic sensors. In SHM systems of welded joints of thin-walled structures, a vibrodiagnostic method is the most promising. Its most important advantage is that it is both effective and relatively low costly. There are two general methods of vibrodiagnostic signal analysis: the most frequently used are spectrum analysis and time waveform analysis. The spectrum analysis concerns changes of natural frequency. In marine exploitation conditions, the frequencies changes might be imperceptible. The first method presented in the article is based on the evaluation of the mean value distribution of the amplitude spectrums calculated with the time window method. Second proposed method was based on the determination of damping decrement in function of time. Due to the complexity of the responses run, the proposed method consisted of calculating the damping decrement using the response approximation with different functions. It has been shown that the changes analysis of damping decrement applied to welded plates enables the assessment of the quality associated with the weld. A calculation algorithm as well as and the exemplary results from the proposed methods used for some selected samples with different type of welds are included in the paper. The results of the tests show that the analysis based on proposed methods indicates that they differ significantly depending on the welds, indicating their quality and cracks that are associated with them.
\end{abstract}

Key words: ship hull diagnostic; welded joints; SHM; damping decrement; time window analysis

\section{Introduction}

Among various means of transport, maritime transport (except for the air transport) is exposed to relatively highest risk. Seagoing vessels often work under extremely difficult environmental conditions. Moreover, maritime structures like marine vessels, submarines and 
offshore structures are exposed to the influence of aggressive marine environment for a very long time. The structures surrounded by a harsh marine environment are exposed to long-term cyclic loadings [1] which come from continuously acting sea waves and short-term extreme loads such as severe storms, seaquakes or even collisions. The marine environment causes fast corrosion, erosion and scour processes. Those phenomena increase the size of an existing damage and also initiate its growth $[2,3]$. The example of disastrous damage (fracture) of a bulk cargo ship, due to a very strong stormy weather, is presented in Fig.1. This type of structural damage has a catastrophic impact on the safety of the crew, the marine environment, and the ship's cargo.

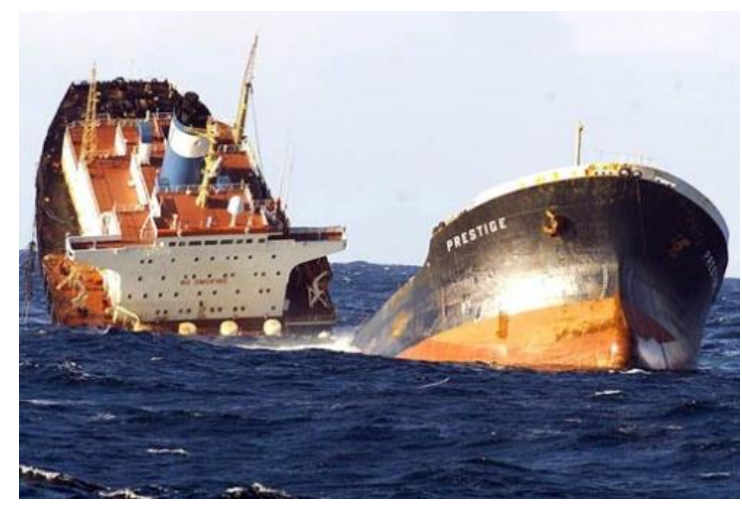

Fig. 1. A maritime disaster resulted from the collapse of the hull structure [http://portalmarynarski.pl]

Each marine vessel and facility works under the supervision of one of the classification societies. They require a detailed periodic safety inspection of the structure from the stage of its design to construction. The welded joints are one of the key elements which undergo precise diagnostic testing. All responsible welds are tested using measurement techniques generally called NDT (Non-Destructive Testing) [4, 5]. Currently, the hybrid tests are becoming the standardized part of NDT. They use mixed approach that combines two or more methods. Hybrid methods are divided into two groups: using the same physical phenomena and acting on the basis of complementary methods of research. An example of a hybrid approach using the same physical phenomenon is the combination of acoustic emission and ultrasound testing. An example of a hybrid approach that is based on acting on the basis of complementary methods of research is surface testing combined with radiographic and/or ultrasonic testing [4, 6]. NDT techniques are well tested and give the results which are sufficiently reliable. However, they have one basic flaw - they are run periodically. In the intervals between tests, the reliability of the structure is uncertain [7, 8]. Particularly in the case of critical events (extremely strong storm, collision, etc.), it is important to note the possibility of further operation of the facility. This information must include the degree of danger of disasters along with the operational parameters, including the time of its safe use. To this end, the new techniques are being developed. They are known as SHM (Structural Health Monitoring) [9, 10].

Structural Health Monitoring is a natural extension of NDT diagnostics of machines and devices. The fundamental difference between SHM and NDT relies on hardware architecture [11]. In case of SHM systems, the network of sensors is integrated with the object while the sensors network used in NDT is external and independent. SHM systems operate on-line, contrary to NDT. The key element of SHM systems is the automation of their operations (e.g. generating the reports, informing the staff about non-standard parameters) on the base of artificial intelligence technology $[12,13]$. Monitoring may be based on the range of, often very different, measurement techniques. The most popular techniques are: methods based on 
testing of characteristics of dynamic structures, acoustic emission, study of elastic waves of Lamb Waves type along with spectra finite element method, thermo-vision methods, ultra-fast framing cameras, layered testing of electromagnetic characteristics, vacuum comparative research and the methods based on fibre optic sensors. The aim of SHM systems is to create the measuring and diagnostic system which would enable to assess the technical condition of the structure continuously and in various environmental and operating conditions. The typical SHM system consists of the net of sensors which continuously measure condition of the structure as well as environmental and operating loads [14]. One of the most important information is strain/stress distribution in the structure. One of the most promising sensors for that purpose are those based on fibre optics technology [15].Two general techniques are analysed. The first one is based on Optical Time-Domain Reflectometer method (OTDR), and the second one is based on Fibre Bragg Grating (FBG) sensors [9, 16]. Amplitude values of the vibration level can be also useable for validation of the structure condition [17]. Typical piezoelectric accelerometers can be used for that type of measurements. The task of system's central unit is to collect and record measurement signals, analyze them (including selection) and to automatically diagnose occurring risks [9].

Works on the elements of the structure monitoring, meaning: detection, localization and identification of damages, are being intensively developed but mostly they are reduced to laboratory and/or preliminary testing [18, 19]. Moreover, shipbuilding works are relatively underdeveloped (e.g. in comparison to aviation). Complete monitoring complements the detection, localization and flaw identification systems by reliable lifetime prediction of the structure and assessments of its further emergency operation [20]. There are no simplistic but reliable mathematical models for static and dynamic evaluation, parameters (reliably relevant for shipbuilding) in the marine industry. These models should be able to be used in systems based on artificial intelligence. Evaluation of the key measurement elements and their effective selection for such a system is essential $[9,16]$.

Monitoring based on vibrodiagnostic techniques is one of the most promising types due to its simplicity and relatively low costs. So far, other techniques do not have practical application. For example, tests which use elastic waves require extremely expensive measuring equipment (e.g. 3D laser) difficult to use in operating conditions for such complex construction as the hull of a ship [21, 22, 23]. One of the most important elements in SHM system is recorded signal analysis. There are two general methods of vibrodiagnostic signal analysis: spectrum analysis (most commonly used) and time waveform analysis. The spectrum analysis concerns changes of natural frequency. In marine exploitation conditions the frequencies changes might be imperceptible [1,24]. The first method built on waveform analysis presented in the article is based on the evaluation of the mean value distribution of the amplitude spectrums calculated with the time window method. The statistical measure used in the form of the mean value is a proposed parameter. The parameter's analysis for a given welded joint may enable an unambiguous assessment of its quality. Second proposed method was based on the determination of damping decrement in function of time. Due to the complexity of the responses run, a proposed method consisted of calculating the damping decrement using the response approximation with different functions. It has been shown that the changes analysis of damping decrement applied to welded plates enables the assessment of the quality associated with the weld.

\section{General assumption for the monitoring system}

Diagnostic system of the ship hull (thin-walled structure) is a target of the authors' research. The work in abovementioned paper is the first step of the planned research. The main goal of presented work stage is determination of diagnostic parameters sensitivity. Time 
window and damping decrement methods have been taken into consideration. After measurement methodology determination, the authors planned next step of the research - research onboard of the real ship (Horyzont II - the ship of Gdynia Maritime University). Excitations will be coming from environmental influencing (e.g. waves). Planned system will be looking for nonlinearities (with using developed diagnostic parameters) in the response signals measured by accelerometers. Proper dynamic characteristics of the ship hull structure will be checked by the system. General assumption of the project of on-line diagnostic (monitoring) system of the thin-walled structure working parameters is analysed in the paper. Three general types of measurements are planned $[5,12,20]$. The first one is a typical vibrodiagnostic measure mentbased on piezoelectric accelerometers (PZT). In marine conditions seismic sensors are useful because frequencies of the sea wave loadings are very low. Characteristic of typical PZT starts from $5 \mathrm{~Hz}$ in contrast to seismic which starts from values below $1 \mathrm{~Hz}$. The sensors will be placed around the most important welds. Global deformations of the ship hull (and external excitations of the foundation system) will be measured by OTDR techniques. Local strain changes (around the most important welding joints) of the structure will be measured by system based on FBG sensors with interrogators. Continuous recording will be performed by planned monitoring system. Online data analysis allows distinguishing between typical signal (for normal ship operations) and unusual signals coming from extreme loadings. Only those unusual signals will be recorded and thoroughly analysed.

\subsection{Optical Time Domain Reflectometer measurement techniques}

An optical time-domain reflectometer (OTDR) is an optoelectronic measurement technique used to characterize an optical fibre $[9,16]$. The "sensor" for OTDR measurement techniques is a typical commercial, telecommunications fibre. An OTDR injects a series of optical pulses into the fibre under test. Light is reflected back from points along the fibre. The strength of the return pulses is measured and integrated as a function of time, and is plotted as a function of fibre length. Optical Backscatter Reflectometer (OBR) instruments are used for strain and temperature measuring along pure fibre optic. OBR measuring device can measure distributed strain and temperature in standard telecom-grade fibres with high spatialresolution. The OBR uses swept wavelength interferometry to measure the Rayleigh backscatter as a function of length in optical fibre. The system allows practical measuring of distributed temperature and strain in standard fibre with millimetre-scale spatial resolution over tens to hundreds of meters of fibre with strain and temperature resolution as fine as $1 \mu \varepsilon$ and $0.1^{\circ} \mathrm{K}$.

Measurement techniques are based on Rayleigh backscatter in optical fibre which is caused by random fluctuations in the index profile along the length of the fibre. The scatter amplitude, as a function of distance, is a random but static property of that fiber can be modelled as a continuous, with a random period. The spectral frequency associated with the Rayleigh backscatter is written in the same form as the reflection frequency of a Bragg grating. Shifts in the fibre index of refraction or in the average perturbation period caused by an external stimulus (like strain or temperature) in turn cause shifts in the local spectral frequency of the Rayleigh backscatter. Accumulated changes along the optical path also manifest themselves as a time shift of the Rayleigh backscatter return loss amplitude pattern. Performing a cross correlation on the backscatter amplitude time domain or frequency domain data accurately measures these spectral and temporal shifts, which are easily scaled to form distributed temperature or strain measurements. An example of the measured signal received from optical backscatter reflectometer offered by Luna firm is shown in Fig. 2. 


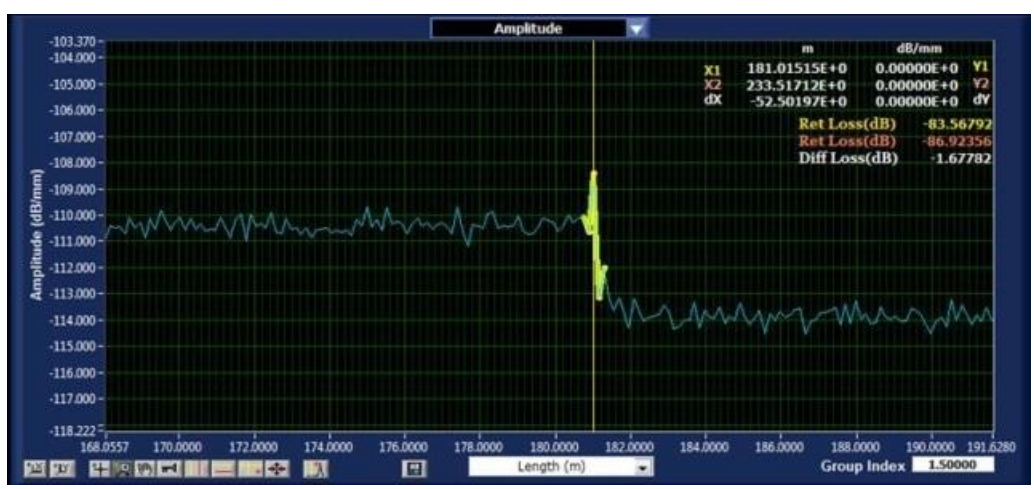

Fig. 2. Example signal from Luna optical backscatter reflectometer

OBR measuring techniques can be used to measure the distributed spectral shift and temporal shift in the Rayleigh backscatter along an optical fiber. This capability facilitates distributed temperature and/or strain sensing along any standard single-mode fiber and this technique enables robust temperature and strain measurements with high spatial resolution and good accuracy. This measurement capability also provides a practical alternative to fiber Bragg gratings sensors and extrinsic Fabry-Perot interferometric sensor in situations where a large number of closely spaced measurements are desired.

On the base of that kind of the system, measurements of global deformations of ship hull are planned. The OTDR based system is dedicated for analysis of quasi-static deformation of the ship hull. The sampling frequency of that system will be equal to $5 \mathrm{~Hz}$. The length of the "sensor" will be between $30-50 \mathrm{~m}$. It will be placed around the midship section. Highest spatial resolution between two measured points is equal to $10 \mu \mathrm{m}$, but for the planned system $10 \mathrm{~mm}$ is enough. Expected strain relative accuracy is about $10^{-5}$. Extreme loadings like storms, ship grounding, and freak waves can be measured by the system [25]. Detailed data of continuous distribution of excitation forces acting on propulsion system will be recorded by OTDR based system.

\subsection{Fibre Bragg Grating measurement techniques}

The systems based on fiber optic technique with Fiber Bragg Grating (FBG) strain sensors are one of the most interesting and promising [13, 17, 26]. In comparison to classical strain measuring method involving electric strain gauges, the new technique using fiber optic technology and FBG sensors is much more stable and the measuring error is much lower. The main benefits of fiber optic (in particular FBG sensors) have been found in their long-term stability and reliability as well as in their insensitivity to the external perturbations like electromagnetic fields [9]. One of the main advantages of FBG sensors is the ability to measure multiple physical parameters [12]. This ability combined with serial multiplexing of FBG sensors allows for multiple parameters to be monitored. This feature is advantageous in applications where minimal intrusion into an environment is required. Another important advantage of FBG sensor is multiplexing ability - many sensors (to over hundred) can be multiplexed to provide measurements across the structure [16]. FBG sensors have several promising assets in comparison to conventional techniques, the main are as follows:

- high sensitivity;

- low sensor's size and mass;

- sensors can be built into the monitored structure (e.g. composite material);

- immunity to electro-magnetic fields;

- applicability to chemical aggressive surroundings; 
- multiplexing (hundreds of sensors in one channel);

- can support thousands of kilometers unrepeated step out distances;

- self-calibrating and free from signal drift (long term stability).

The history of optical fibres reaches back to the 1960s [12]. But these fibres had a damping of $100 \mathrm{~dB} / \mathrm{km}$ caused mainly by the chemical impurity of the glass. Today the damping is $<0.2 \mathrm{~dB} / \mathrm{km}$. In 1978 the effect of photo sensitivity for Germanium doped fibres has been found. Exposure to ultraviolet light induces a permanent change of the refractive index. The next step was to use this effect and write Bragg gratings into fibres which then can reflect very small wavelength peaks. The wavelengths of these peaks change with strain and temperature. First commercial FBG sensor was available in 1995.

Bragg gratings are written into single-mode fibres. These fibres consist of a very small inner core (diameter 4-9 $\mu \mathrm{m}$ ) and an outer part (cladding) of pure glass (SiO2) of $125 \mu \mathrm{m}$ diameter. The core has a higher refraction index caused by high Germanium doping. The core has a higher refraction index caused by high Germanium doping. The difference of refraction index between inner core and cladding causes the light to propagate only inside the small core. The glass fiber is coated with acrylate, polyimide or organic modulated ceramic to protect it especially against water and hydrogen which causes crack growing and can reduce the mechanical stability.

Each single fringe reflects a very small part of all incoming wave. The reflection factor per single fringe is in the range of $0.001 \%$ up to $0.1 \%$, depending on how much energy was used to write the Bragg grating and on the percentage of Germanium doping of the fibre core. Each single fringe reflects light with different phase shifts. Therefore, interference is a reason why the most of the light is erased. But the reflections with equal phase shift accumulate in a strong reflection peak. The reflection of whole grating is the sum of all these thousands of very small single reflections. Reflected light travels forth and back in the fibre, therefore reflected light beams of the single grids are in phase if an integer of light wavelength fits into two times the grid distance. The grid spacing can be calculated as follows:

$$
\Lambda=\frac{\lambda_{0}}{2 n}
$$

where:

$$
\begin{aligned}
& \lambda_{0}-\text { wavelength peak, } \\
& n-\text { refraction index of the fibre. }
\end{aligned}
$$

Because typical values of the FBG is: $\lambda_{0}=1550 \mathrm{~nm}$ and $\mathrm{n}=1.46$, the grid spacing should be equal to $530 \mathrm{~nm}$. If the length of the FBG sensor is equal to $5 \mathrm{~mm}$ then the number of fringes in the single sensor should be approximately equal to ten thousand.

A FBG sensor (see Fig. 3) has a periodic structure [16]. When light within a fibre passes through a FBG, multiple reflections take place along the entire length of the grating due to the variations in refractive index. Constructive interference between the forward wave and the contra-propagating light wave occurs when the wavelength of the propagating light in the fibre doubles the grating pitch. This leads to narrowband back-reflection of light. A fibreoptic Bragg grating sensor acts as a filter for light running along the single-mode fibre line. Reflected wavelength $\lambda_{B}$ is a function of sensor's strain (affected by external stress and/or temperature field). The reflected wavelength is known as the Bragg wavelength $\lambda_{B}$ and given by:

$$
\lambda_{B}=2 \cdot n_{e} \cdot \Lambda
$$


where:

$n_{e}$ - effective refraction index of the fiber core,

$\Lambda$ - the period of the index modulation.

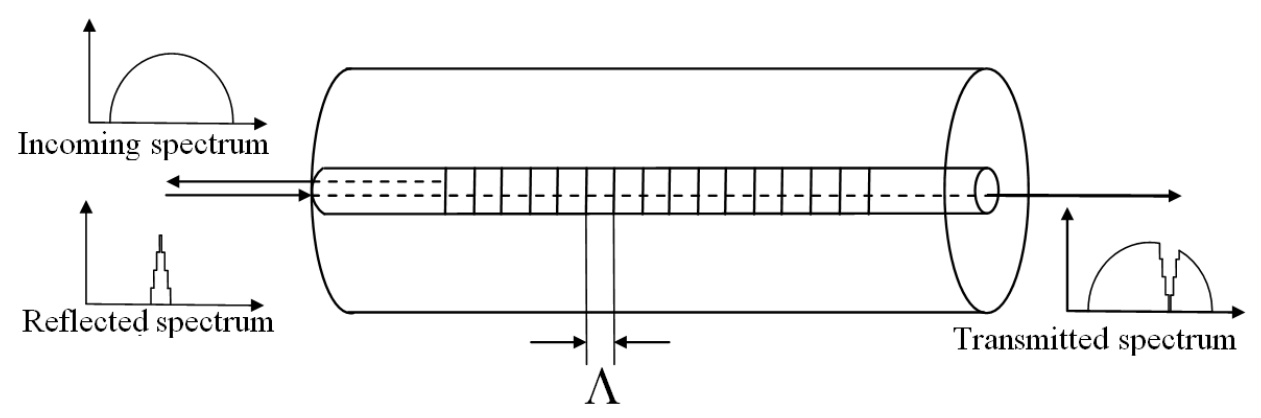

Fig. 3. Scheme of a FBG sensor with reflected and transmitted spectra

Both $n_{e}$ and $\Lambda$ depend on temperature and strain, therefore the Bragg wavelength is sensitive to both strain and temperature. The expansion coefficient of the fibre is negligibly low. The biggest impact results from the temperature dependent change of the refraction index. When a fibre is fixed to a specimen, the FBGs signal changes with the mechanical and temperature caused strain of the specimen. Therefore the thermal coefficient is equal to expansion coefficient of the specimen (not glass). It leads to equation for strain-measuring FBGs:

$$
\varepsilon_{m}=\frac{1}{k} \cdot \frac{\Delta \lambda_{B}}{\lambda_{B}}-\left(\alpha_{s p}+\frac{\alpha_{\delta}}{k}\right) \cdot \Delta T
$$

where:

$k$ - gauge factor,

$\alpha_{\mathrm{sp}}-$ expansion coefficient of the specimen,

$\alpha_{\delta}$ - change of the refraction index.

Because temperature has a very strong impact on the FBG sensors, precise strain measurements can only be achieved with proper temperature compensation. When the FBG sensor is fixed to the specimen on a surface without mechanical strain, it works as temperature compensation sensor. In measurements at very high temperatures (hundreds ${ }^{\circ} \mathrm{C}$ ) it must be taken into account that the base wavelengths of the sensor change considerably with temperature.

If FBG sensor is strained, the wavelength of the reflection peaks is shifted. It is necessary to measure these shifts very precisely. Resolution and short-term stability of $\pm 1 \mathrm{pm}$ is required [26, 27]. For laboratory investigations, interferometers are often used. In the commercial equipment usually other principles are applied. An example of modern FBG sensor produced by Micron Optics is presented in Fig. 4. Nowadays the top-class instruments are using tuneable lasers. The interrogator uses broad-band light source and therefore only a very small part of the light energy is related to the small bandwidth of a BFG. Therefore, the reflected peak energy is very low. A tuneable laser concentrates all its energy in an extremely small bandwidth and by sweeping over the whole bandwidth range it scans the spectrum with high power and can provide an excellent signal-to-noise ratio. 
Muc Adam, Murawski Lech, Szeleziński Adam
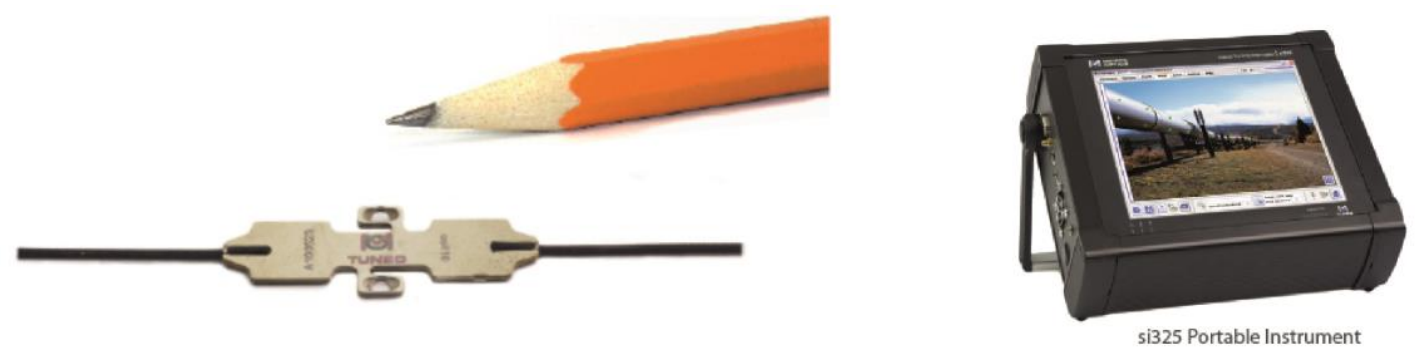

Fig. 4. Micron Optic FBG sensor and Micron Optic portable interrogator

The FBG sensors will be mounted in the midship section [23, 25]. Monitoring system based on the FBG sensors will measure local strains (stresses) of the ship hull. The sampling frequency of that system will be equal to $20 \mathrm{kHz}$. Therefore, that part of monitoring system is dedicated for high-frequency dynamic analysis of extreme loadings. Obviously, quasi-static strains will be also recorded. The typical length of the sensor is between 2-20 mm. For our local strain measurements, $10 \mathrm{~mm}$ is the optimum length of the sensor. Three FBG sensors (triangle or star type of arrangement) for each measured point are planned. The sensitivity and accuracy of FBG sensor with a typical interrogator are even higher in comparison to OTDR system; therefore, it is sufficient for our research.

\section{Laboratory measurements of the sample of welded joints}

The test stand to conduct the testing of welded joints using the vibrodiagnostic method [5] was constructed at the Faculty of Marine Engineering at Gdynia Maritime University. The structure of the stand and its most important parts are presented in Fig. 5. The stand includes the holder (1) which can be used to install the plates (welded test pieces) horizontally - 4point mounting or vertically - 2-point mounting, vibration analyzer (2) produced by Bruel \& Kjaer, two accelerometers (3), modal impact hammer (4) with three interchangeable heads i.e. metal, silicon, and teflon.

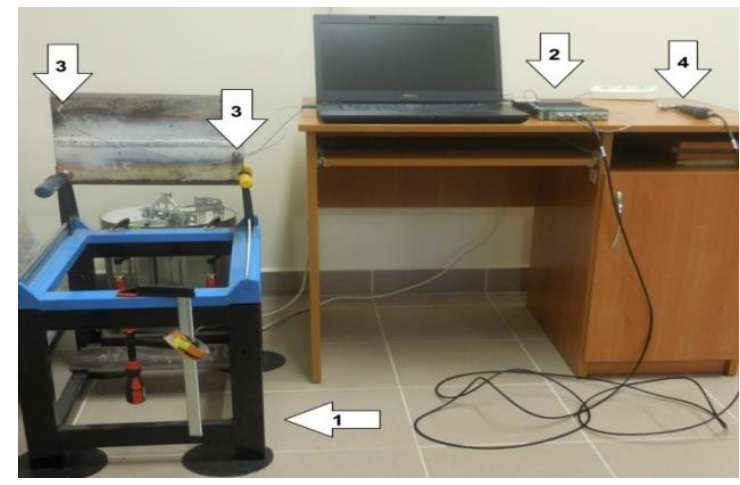

Fig. 5. The apparatus for welded joints testing with vibration based methods

During the process of preliminary tests, the plates were installed vertically on the holder as it is presented in Fig. 5. The tests were conducted on four plates. The plate marked by number $\boldsymbol{O}$ was homogenous and did not have welded joints. The other three included welded plates that were marked by number: 2202 - the plate that did not have any flaws, 2127 - the plate that had flaws in the form of boundary bonding and 2132 - the plate with simulated cracks along the whole length. All test pieces that had welded joints were tested using the radiographic method before the measurement. It enabled the assessment of the joints quality along with identification and placement of flaws in the plates 
The measurements of vibration generated by the plates were taken in the prepared test stand. The vibration was caused by the impact hammer with different heads: metal, silicon, and teflon. The places of strokes are presented in Fig. 6, described by means of $\boldsymbol{F 1}, \boldsymbol{F} \mathbf{2}$, and $\boldsymbol{F 3}$. The results were read by the accelerometers $\boldsymbol{A C C 1}$ and $\boldsymbol{A C C 2}$.

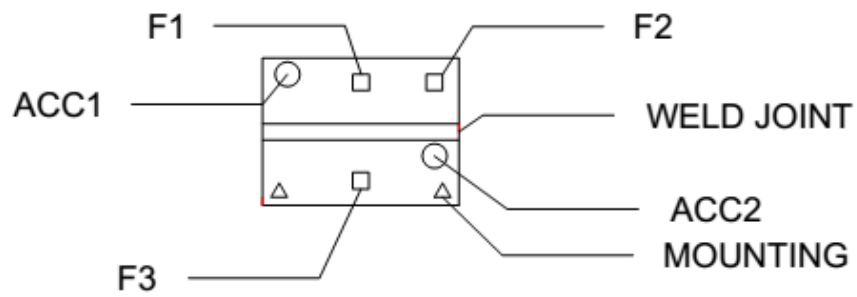

Fig. 6. Schematic diagram showing the arrangement of accelerometers (ACC1, $A C C 2)$, places of strokes $(F 1, F 2$, $F 3)$ and plates mounting places in the holders $(\triangle)$

In the article, the calculations were made for the measurement results obtained using a metal head installed on a modal hammer.

\section{Time window method in time-frequency analysis}

The time window method enables simulation of concurrent signal analysis in the field of frequency and time. This opportunity is often used in the analysis of technical systems dynamics, especially electrical or electronic ones. It is used in mechanical systems testing very rarely. In case of time window method, the key element which influences the quality of results is a proper selection of the type and width of the time window. Then the FFT analysis (Fast Fourier Transform) is carried out for each of windows.

The time windows method was used in conducted tests in order to analyze the responses which were recorded by accelerometers placed on plates with welded joints. The tests were done for rectangular window in terms of which various time intervals were checked. The decision to choose the rectangular window comes from the willingness to reduce the distortions of recorded course of response to the least extent. This kind of situation often takes place in case of more complex windows. Then at the cost of accepted changes introduced from the signal, it is possible to eliminate the part of distortions through the window.

Conducted tests aimed at the optimal coverage of spectrums characteristic changes which determine the quality of welds and possible defects. Eventually, the chosen width of the window was $10 \mathrm{~ms}$. The examples of set of amplitude spectrums calculated for time windows are presented in Fig. 7 and 8. The figures contain chosen results obtained for the metal head. The first range covers the time windows from 1 to 12 and the second one from 10 to 21 . The three time windows, from 10 to 12 , are been repeated in both figures in order to show the transition from one range to another. The analyses were done for the plate without the weld and with different welded joints. The plate response to the signal made with a modal impact hammer with metal and teflon head was registered by accelerometer for all plates. 

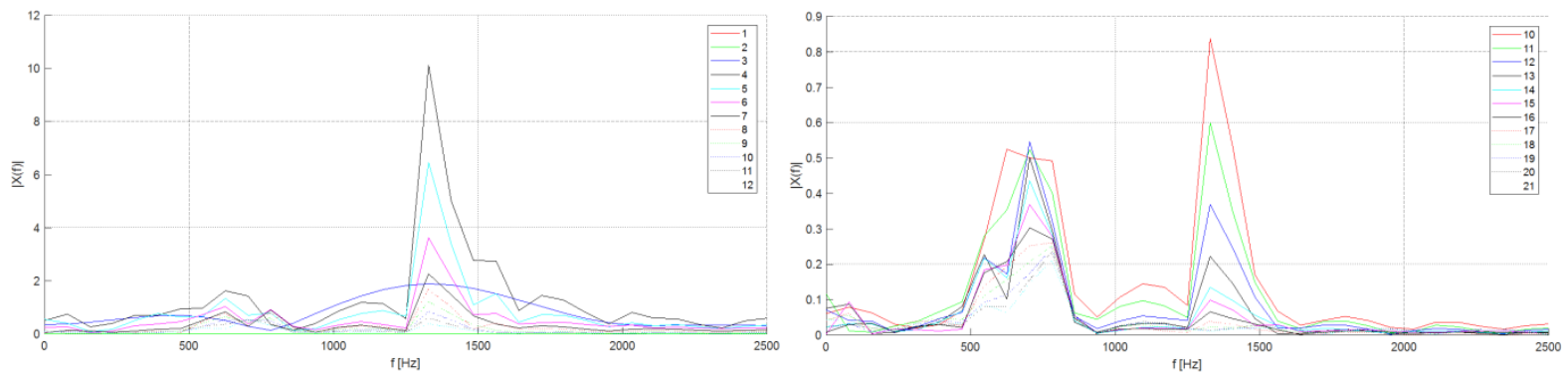

Fig. 7. Amplitude spectrums calculated by time window method for the plate without flaws in the weld
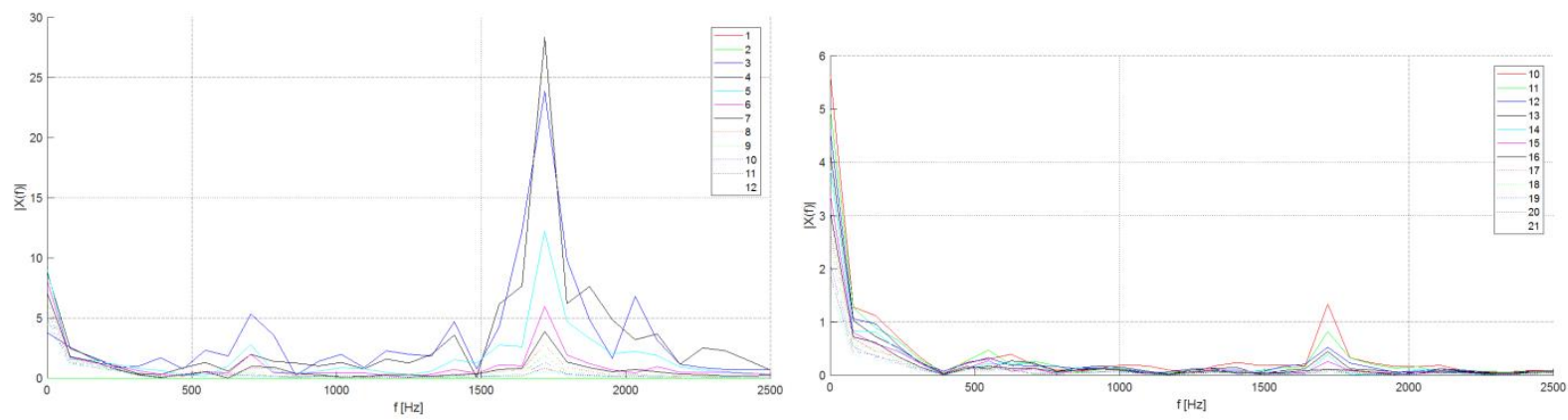

Fig. 8. Amplitude spectrums for the plate with flaw in the form of boundary bonding

The comparison analysis of amplitude spectrums, calculated for each window, shows nonlinearities of structures of damaged welded plates. If the quality of welded joint is worse, the nonlinearities are stronger, that is when the defect is shown in the welded joint. In presented example (Fig. 7 and 8) this kind of situation concerns welded plate with the flaw in form of boundary bonding. Moreover, the preliminary analysis of spectrums shows that most diagnostic information comes from first ten time windows which mean about $100 \mathrm{~ms}$ of analyzed response registered by accelerometer. Presented amplitude spectrums are characterized by similar character of distribution, especially in terms of harmonics, however, important diagnostic information is given by the spectrum of higher harmonics, which analysis requires additional mathematical operations. Proposed parameter to compare the amplitude spectrums calculated for each window of the same sample and to evaluate the nonlinearity resulting from welded joint in a plate was the mean distributions of amplitude spectrums. The mean value is a measure of descriptive statistics which was calculated from the equation (4).

$$
\overline{|v|}=\frac{\sum_{i=0}^{N}\left|v\left(f_{i}\right)\right|}{N}
$$

where:

$|v|$ - the mean of amplitude spectrum velocity calculated for the time window,

$f_{i}$ - the frequency of $\mathrm{i}^{\text {th }}$ harmonic,

$N$ - the number of harmonics.

The preliminary tests have shown that the analysis of only mean values is not sufficient. However, the relevant diagnostic information about the quality of welded joint is given by mean value distribution for the spectrums obtained from the whole response of time windows. Fig. 9 shows some examples of amplitude spectrums taken from chosen time windows and the values calculated for them. 
The distribution shown in Fig.10, presents the alteration of the mean value calculated for the amplitude spectrum in given window in function of window number for a chosen welded plate. Presented characteristics show that the mean distribution for windows calculated for the sample without the weld (marked as number 0) differs significantly in comparison to mean distribution of other samples with weld or samples with a flaw in welded joint (marked as: 2202, 2132, 2127). This difference is especially applicable in terms of the level of mean values and cyclic value change between local maximums and minimums. It is also possible to notice that the mean value distributions for the samples with the weld and a flaw are characterized by lower value than for the plates with weld and without flaws.
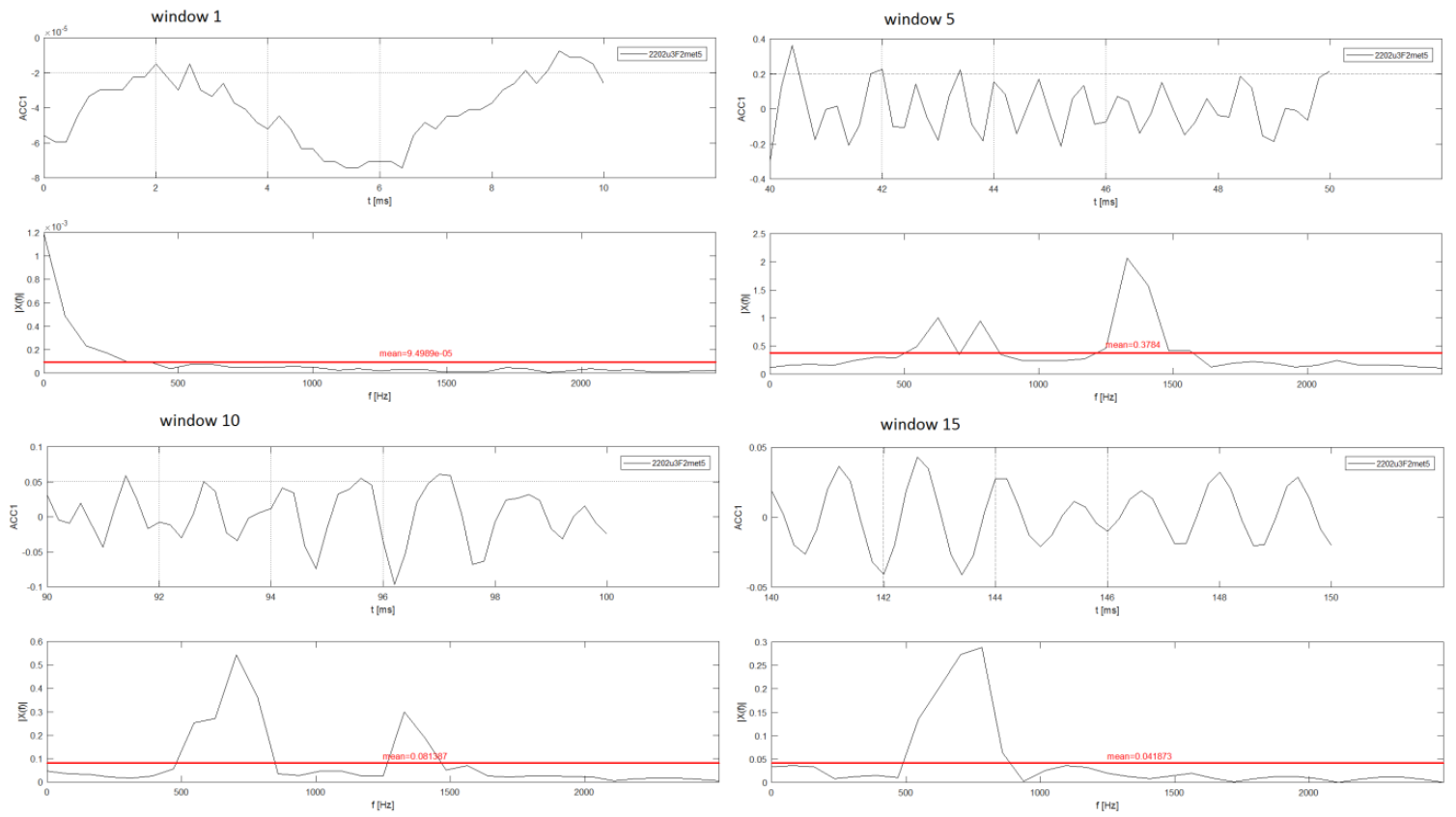

Fig. 9. Amplitude spectrums in chosen windows with the designated mean value

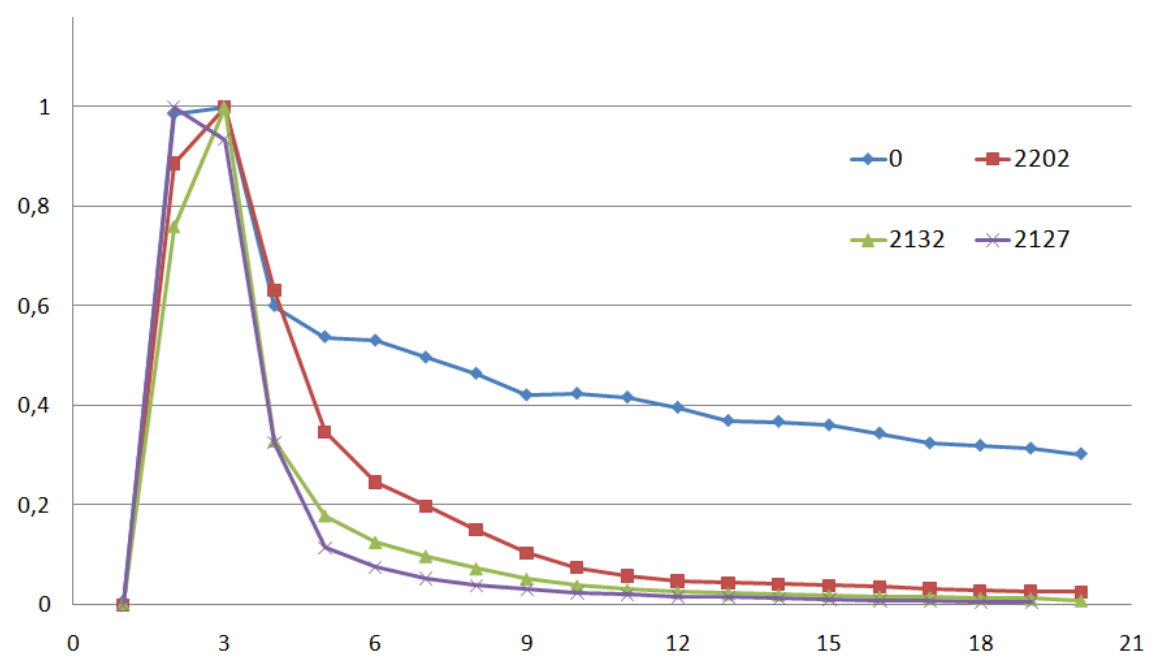

Fig. 10. Standardized distribution of mean value of the spectrums for windows in function of window number

\section{Applying the damping decrement distribution to flaw assessment of welded joints}

Using the vibrodiagnostic method in tests on welded joints allows analyzing the amplitudes of structure vibrations, in this case, made by modal hammer. While testing, it is 
possible to record few responses - vibration amplitudes. In order to achieve that, the accelerometers were placed in different locations on the tested plate. Recorded responses take the form of damped oscillatory motion. The weld (including its quality), which connects two plates, influences the disappearance speed of diagnostic signal (the speed of energy dissipation), and this is why it is possible to use a damping decrement in its assessment. The dumping decrement is commonly used in assessing the dynamics of many mechanical systems. However, due to the variable nature of response in time, it is impossible to apply regular formula for the logarithmic decrement, expressed as a time-independent constant. Two forms of logarithmic decrement were derived in this work and they are represented by equation(5) and (6). Statement (5) is used to determine averaged structure damping in regard of maximal amplitude; statement (6) is used to assess the damping changes during single vibration periods or its groups.

$$
\begin{aligned}
& \Psi_{I}=\frac{1}{n} \cdot \ln \left(\frac{A_{0}}{A_{n}}\right) \\
& \Psi_{I I}=\frac{1}{n-m} \cdot \ln \left(\frac{A_{m}}{A_{n}}\right)
\end{aligned}
$$

where:

$\psi$-logarithmic decrement,

$\mathrm{A}_{0-\mathrm{n}, \mathrm{m}}-$ subsequent amplitude peak values,

$\mathrm{n}, \mathrm{m}$ - subsequent number of amplitude.

In case of welded joints, damped oscillatory motions of responses recorded by accelerometers are characterized by uneven distribution of maxima and minima. Due to variable changes of vibration speed and the need to calculate damping decrement, the possibility of approximations of response runs was checked using the functions which are generally represented by formula (7). In order to choose a proper approximating function, the comparative analysis was conducted, in which the approximations obtained by polynomials from second to fifth degree were collated with an exp function.

$$
\begin{gathered}
v_{1}(t)=\sum_{i=0}^{N} a_{i} \cdot t^{i} \\
v_{2}(t)=b \cdot \exp (-c \cdot t)
\end{gathered}
$$

where:

$v(t)$-function approximating the course of speed,

$a_{\mathrm{i}}$ - i-thconstant for the polynomial,

$b, c$ - constants for the exp function.

The exemplary results of approximations for the response recorded for the sample without flaws and the sample with the flaw in the form boundary bonding are presented in Fig. 11 and 12.The tests are performed using a metal head on the modal hammer. 


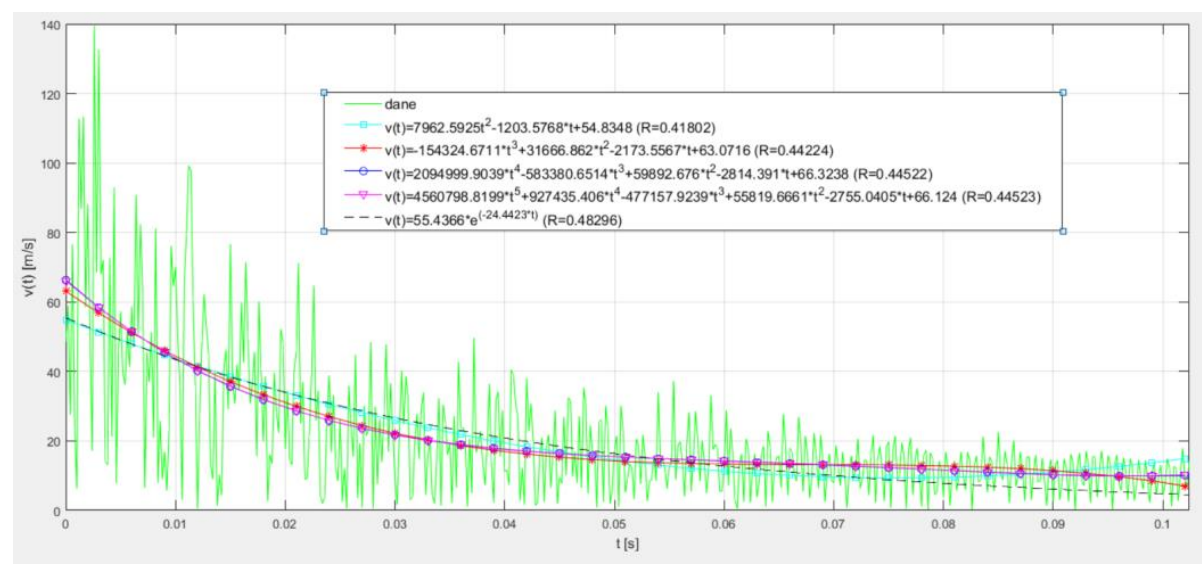

Fig. 11. Example of approximation of the response received for the welded plate without flaws (2202)

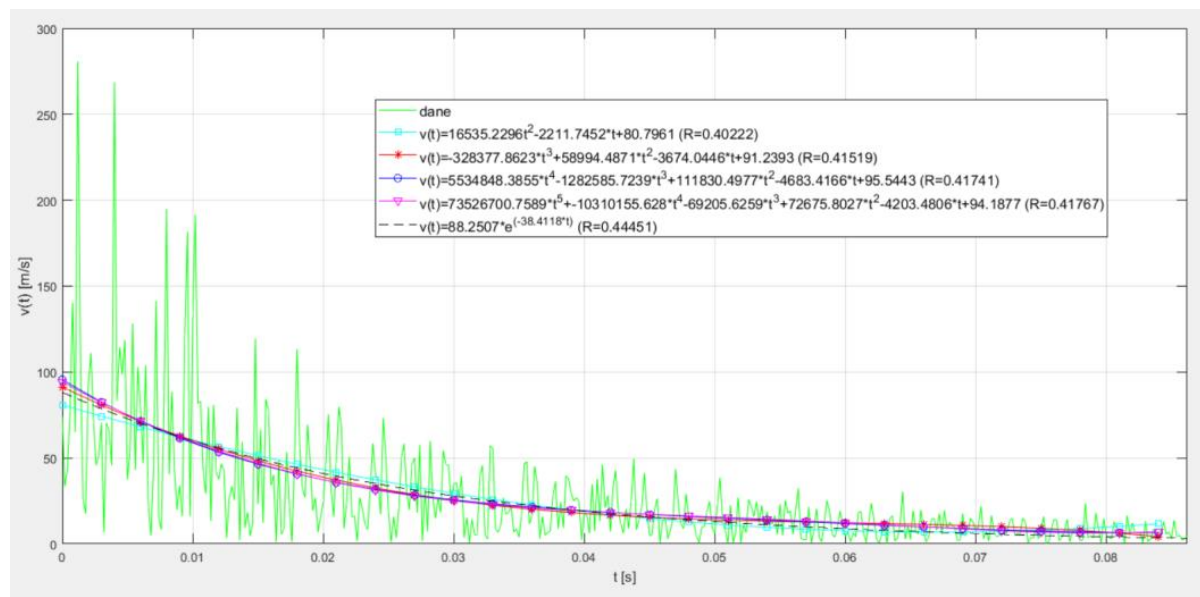

Fig. 12. Example of approximation of the response received for the welded plate with flaw in the form of boundary bonding (2127)

By verifying the results of the approximation, it may be concluded that the seconddegree polynomial is not a proper one in the test case because in regard to small amplitudes it deviates from true values of responses increasing the approximation error. However, the other functions allow determining the approximate response in a satisfactory way. At the same time, it can be noticed that increasing the degree of polynomials above 4 does not improve the approximation of received response.

Equations (5) and (6) were used to calculate the damping decrement. The following figures present the results obtained for formula (5). The first formula allows calculating the decrement distribution in regard of maximal amplitude, and the second one in regard to chosen range. For the results obtained from each approximating function, the damping decrement was calculated in regard to maximal value $\left(A_{o}\right)$. The damping decrement obtained with approximation by exp function is characterized by linear change. Moreover, it was considered to be the reference for other results. Fig. 13 shows changes of damping decrement for the homogenous plate without welded joint along the different approximating functions. It is noticeable that the damping decrements distributions determined for the plate without the welded joint represent the constant type. It reflects the uniform damping, which is observable for plates showing characteristics of linear structure both materially and geometrically. 


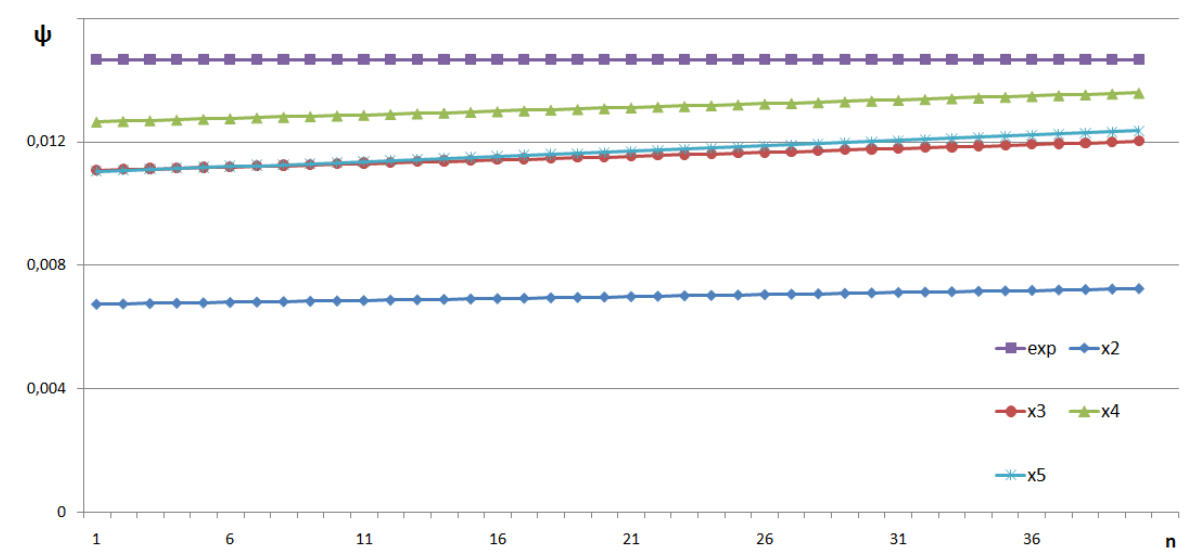

Fig. 13. Values of damping decrement changes for the plate without weld (0)

It is possible to observe higher, time-varying damping for material with a good weld (Fig. 14).Therefore, decrements runs are clearly curved and become concurrent with a decrement calculated from exp function. The intersection with the reference characteristic of the decrement occurs at the $41^{\text {st }}$ peak amplitude of response. This effect is even more noticeable in case of the welded plate with the flaw in the form boundary bonding(Fig. 15) because the intersection occurred already at the $31^{\text {st }}$ peak amplitude of the response.

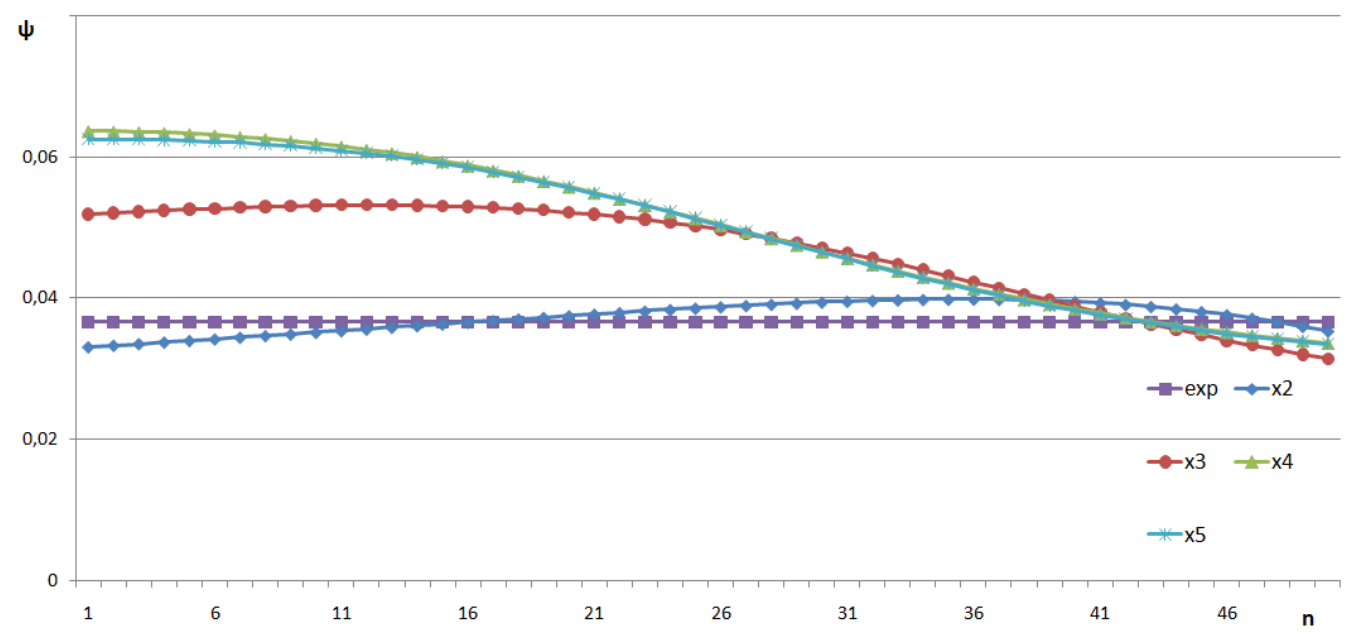

Fig. 14. Values of damping decrement changes for the plate with a weld without flaws (2202) 


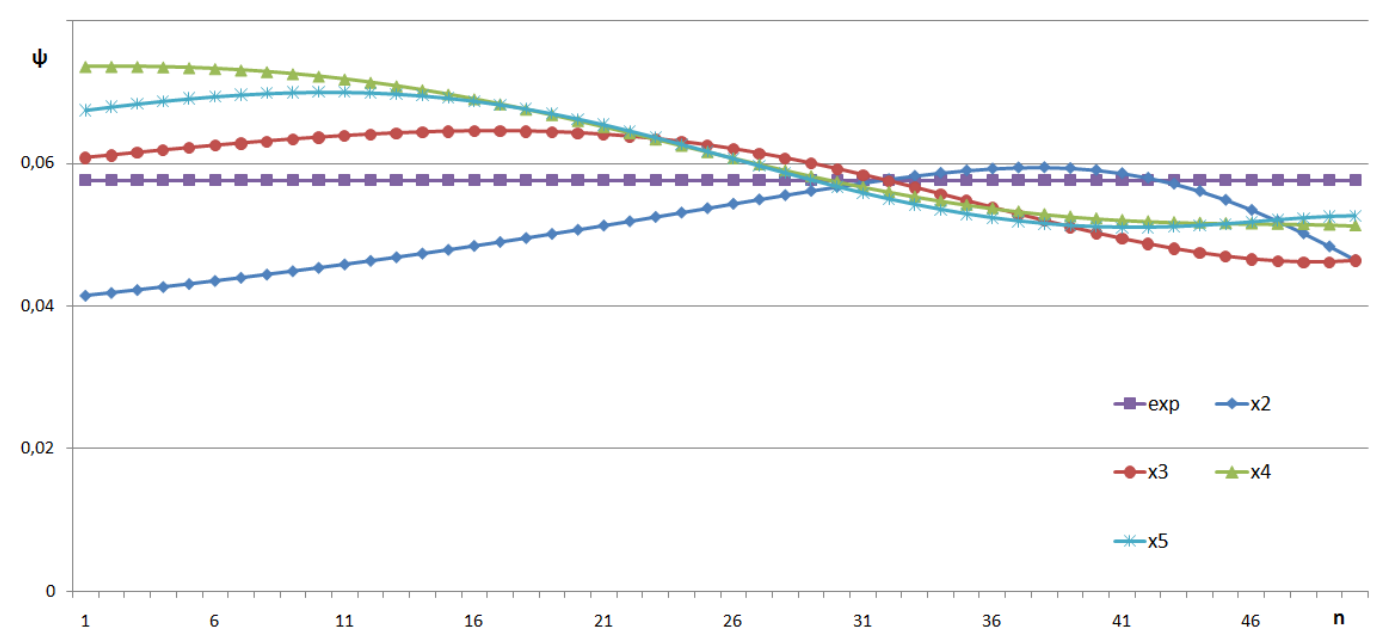

Fig. 15. Values of damping decrement changes in time for the plate with a weld having the flaw in the form boundary bonding (2127)

\section{Conclusions}

The presented analysis methods of the response obtained in the vibrodiagnostic testing of welded plates allow concluding that it will be possible to detect the damages of the welded joint in autonomic maritime structural health monitoring. The condition and quality of the weld joint for given plate can be obtained from diagnostic information of the mean value distribution analysis of amplitude spectrums calculated for the time window method. It is possible to use this parameter to detect some defects (cracks) in welds in systems made for autonomous SHM system. Because of similarities between presented characteristics and Poisson distribution, it is possible to introduce proposed method to evaluation of the welded joints on the basis of one parameter which would be expected value calculated for this distribution and marked as $\lambda$. Application of time windows method to evaluation of welded joints enabled the analysis of responses from accelerometers in the field of time and frequency. All differences of frequency characteristics in windows show the nonlinearity of the system and also additional dissipation of vibration energy which is a sign of construction inconsistency. Additional dissipation means flawed welded joint.

In the second presented method, for a plate made of one material and without weld, the damping decrement distribution obtained for different approximating functions is practically linear and parallel to the characteristic of the reference value. In the other cases, i.e. for plates with welded joints, the characteristics of damping decrement clearly curve and tend to intersect with the characteristic of reference decrement. The results show that the characteristics of damping decrement curve faster for the plates which weld has a flaw. Applying various functions to response approximations allowed assessing their usefulness in concluded calculations. From the comparative analysis of the results obtained for the selected functions, it is clear that the second-degree polynomial should not be used in these calculations. On the other hand, increasing the polynomial above the fourth degree also seems unreasonable as the results overlap. As the characteristics show, using a third-degree polynomial gives an incomplete result that is lower than the result obtained for the fourthdegree polynomial.

Proposed evaluation methods of welded joints require further testing of larger number of samples with various flaws in welds. 
Muc Adam, Murawski Lech, Szeleziński Adam
Methods of crack detection in marine structures' welded joints based on signals' time waveform analysis

\section{REFERENCES}

[1] Mauro F., Nabergoj R.: An enhanced method for extreme loads analysis,Brodogradnja/Shipbuilding Vol. 68, No. 2, pp.79-92, 2017.

[2] Recho N.: Fracture Mechanics and Crack growth, John WILEY, March 2012.

[3] Vukelić G., Brnić J.: Predicted Fracture Behavior of Shaft Steels with Improved Corrosion Resistance, Metals, Vol. 6 (2), pp. 1-9, 2016. https://doi.org/10.3390/met6020040.

[4] Lewicka-Romicka A.: Badania nieniszczące. Podstawy defektoskopii, Wydawnictwo Naukowo Techniczne, Warszawa 2001.

[5] Szeleziński A., Murawski L., Muc A.: Analysis of ability to detect defects in welding structures with usage of dynamic characteristics spectrums, Journal of KONES Powertrain and Transport, Vol. 23, No 2,pp.365-372, Warsaw 2016.

[6] Dudzik S.: Wyznaczenie głębokości defektów materiałowych z zastosowaniem aktywnej termografii dynamicznej i sztucznych sieci neuronowych, Wydawnictwo Politechniki Częstochowskiej, Częstochowa 2013.

[7] Grous A., Lassen T., Recho N.: Estimation of the uncertainties on the fatigue reliability of a welded assembly basedon Power-law accelerated Birnbaum-Saunders life models, Chapter in the book: Safety, Reliability, Risk and Life-Cycle Performance of Structures\& Infrastructures - Deodatis, Ellingwood\&Frangopol Taylor \& Francis Group, London 2013.

[8] Krajewski A., Hudycz M.: Zapewnienie jakości i kontrola złączy spajanych, Oficyna Wydawnicza Politechniki Warszawskiej, Warszawa 2015.

[9] Glisic B., Inaudi D.: Fiber Optic Methods for Structural Health Monitoring, John Wiley \& Sons, Hoboken, West Suessex 2007. https://doi.org/10.1002/9780470517819.

[10] Murawski L., Ostachowicz W., Opoka S., Mieloszyk M., Majewska K.: Practical application of monitoring system based on optical sensors for marine constructions, Key Engineering Materials, Vol. 518, pp 261-270, 2012. https://doi.org/10.4028/www.scientific.net/KEM.518.261.

[11] Wildy S. J., Kotousov A. G., Codrington J. D.: A newpassive defect detection technique based on the principle ofstrain compatibility,Smart Material Structure, Vol. 17, 8pp.,2008.

[12] Krawczuk M., Kudela P., Majewska K, Malinowski P., Murawski L., Opoka S., Ostachowicz W., Radzieński M., Wandowski T., Żak A.: Monitorowanie stanu technicznego konstrukcji i ocena jej żywotności, Wydawnictwo Naukowe Instytutu Technologii Eksploatacji, pp. 196, Gdańsk 2012.

[13] Chan T.H.T., Yu L., Tam H.Y., Ni Y.Q., Liu S.Y., Chung W.H., Cheng L.K.: Fiber Bragg grating sensors for structural health monitoring of Tsing Ma bridge, Background and experimental observation, Engineering Structures, Vol. 28, pp. 648-659, 2006. https://doi.org/10.1016/j.engstruct.2005.09.018.

[14] Murawski L., Ostachowicz W., Mieloszyk M., Majewska K.: Monitoring Possibility of Sailing Ships' Masts,Proceedings of the sixth European Workshop on Structural Health Monitoring EWSHM-2012,pp. 1409-1415, July 2012.

[15] OpokaS., MurawskiL., WandowskiT., MalinowskiP., OstachowiczW.: Static-Strain Level Change Together with Detection of Transient Signal as Damage Indicator for Truss and Frame Structures,Strain, Vol. 49 (4), pp. 287-298, August 2013. https://doi.org/10.1111/str.12037.

[16] Udd E.: Fiber Optic Sensors: An Introduction for Engineers and Scientists, John Wiley \& Sons, New Jersey 2006.

[17] Opoka S., Murawski L., Wandowski T., Malinowski P., Ostachowicz W.: Damage detection experiment on offshore platform leg model with usage of fibre optic technique based on FBG sensors, Proc. 8th International Conference on Condition Monitoring and Machinery Failure Prevention Technologies Cardiff UK, July 2011.

[18] Li H.N., Li D.S., Song G.B.: Recent applications of fiber optic sensors to health monitoring in civil engineering, Engineering Structures, Vol. 26, pp. 1647-1657, 2004. https://doi.org/10.1016/j.engstruct.2004.05.018.

[19] Todd M. D.: Bragg grating-based fibre optic sensors in structural health monitoring, Philos. Trans. R. Soc., A 365, pp. 317-343,2007.

[20] Wang G., Pran K., Sagvolden G., Havsgard G.B., Jensen A.E., Johnson G.A., Vohra S.T.:Ship hull structure monitoring using fibre optic sensors, Smart Material and Structures, Vol. 10, pp.472-478,2001. https://doi.org/10.1088/0964-1726/10/3/308. 
[21] Iijima K, Yao T, Moan T.: Structural response of a ship in severe seas considering global hydroelastic vibrations. Marine Structures, Vol. 21, pp. 420-445, 2008.

https://doi.org/10.1016/j.marstruc.2008.03.003.

[22] Senjanović I., Vladimir N., Tomić M., Hadžić N., Malenica Š.: Some aspects of structural modelling and restoring stiffness in hydroelastic analysis of large container ships, Ships and Offshore Structures, Vol. 9, No. 2, pp. 199-217, 2014. https://doi.org/10.1080/17445302.2012.762728.

[23] Murawski L.: Static and DynamicAnalyses of Marine Propulsion Systems, Oficyna Wydawnicza Politechniki Warszawskiej, Warszawa 2003.

[24] Fontea M., Duartea P., Anesb V., Freitasb M., Reisb L.: On the assessment of fatigue life of marine diesel engine crankshafts, Engineering Failure Analysis, Vol. 56, pp. 51-57, 2015. https://doi.org/10.1016/j.engfailanal.2015.04.014.

[25] Andersen IMV, Jensen J.J.: Measurements in a container ship of wave-induced hull girder stresses in excess of design values. Marine Structures, Vol. 37, pp. 54-85, 2014. https://doi.org/10.1016/j.marstruc.2014.02.006.

[26] Sante R.D., Donati L., Troiani E., Proli P.: Reliability and Accuracy of Embedded Fiber Bragg Grating Sensors for Strain Monitoring in Advanced Composite Structures, Metals and Materials International, Vol. 20, No. 3, pp. 537-543,2014. https://doi.org/10.1007/s12540-014-3020-7.

[27] Webb S., Peters K., Zikry M., Vella T., Chadderdon S.,Selfridge R., Schultz, S.: Wavelength hopping dueto spectral distortion in dynamic fiber Bragg grating sensormeasurements. Meas. Sci. Technol. Vol. 22, pp. 1-11,2011. https://doi.org/10.1088/0957-0233/22/6/065301.

$\begin{array}{lll}\text { Submitted: } & \text { 12.06.2017. } & \text { Adam Muc } \\ & & \text { Lech Murawski } \\ \text { Accepted: } & 09.04 .2018 . & \text { Adam Szeleziński } \\ & & \text { Gdynia Maritime University } \\ & \text { ul. Morska 81-87, 81-225 Gdynia, Poland } \\ & \text { tel.: +48586901 480, fax: +48586901399 } \\ & \text { email: a.muc@we.am.gdynia.pl }\end{array}$

